\title{
Study of the radiotherapy sensitization effects and mechanism of capecitabine (Xeloda) against non-small-cell lung cancer cell line A549
}

\author{
J.J. Zhu' ${ }^{1}$, J.J. Shan ${ }^{2}$, L.B. Sun ${ }^{1}$ and W.S. Qiu ${ }^{1}$ \\ 1'Department of Oncology, The Affiliated Hospital of Qingdao University, \\ Qingdao, Shandong Province, China \\ ${ }^{2}$ Shandong People's Hospital of Juye County, Shandong Province, China \\ Corresponding author: J.J. Zhu \\ E-mail: jingjuanzhu@126.com
}

Genet. Mol. Res. 14 (4): 16386-16391 (2015)

Received June 22, 2015

Accepted September 25, 2015

Published December 9, 2015

DOI http://dx.doi.org/10.4238/2015.December.9.7

\begin{abstract}
The purpose of this study was to explore the radiotherapy sensitization effects and the mechanism of capecitabine (Xeloda) against the non-small-cell lung cancer cell line, A549. $y-\left[{ }^{60} \mathrm{Co}\right]$ radiation was used as the intervention method. Proliferative inhibition of capecitabine on A549 cells was determined by the CCK-8 method. The effects of capecitabine on the apoptosis rate and cell cycle distribution of A549 were detected with the flow cytometric method. We found that capecitabine inhibited the proliferation of A549 in a dose-dependent manner, notably increased the cell apoptosis rate and blocked the cellular G0/G1 phase after radiotherapy by $\mathrm{Y}-\left[{ }^{60} \mathrm{Co}\right]$. Therefore, capecitabine can significantly increase the radiosensitivity of A549; its mechanism may be related to cell cycle arrest and induction of apoptosis.
\end{abstract}

Key words: Capecitabine (Xeloda); Non-small-cell lung cancer cell line A549; Radiation sensitive; Apoptosis 


\section{INTRODUCTION}

Many cancer patients worldwide have received radiotherapy to control tumor growth. Although great technological progress has been made in radiation dose control, optimal radiation doses still cannot be used on some tumors owing to the risk of damage to normal tissues. One effective means of solving this problem is enhancing the radiosensitivity of tumor cells. Capecitabine (Xeloda) has been widely used in the radiotherapy of digestive tract cancer (Hameed and Cassidy 2011; Miger et al., 2014). There are fewer reports on its effects in the radiotherapy of non-small-cell lung cancer. In this study, non-small-cell lung cancer cell line A549 was treated with different concentrations of capecitabine to observe the cytotoxicity and radiosensitization of capecitabine and investigate its possible mechanism, which could provide the experimental basis for radiotherapy of non-small-cell lung cancer with capecitabine.

\section{MATERIAL AND METHODS}

\section{Cell lines and reagents}

Non-small-cell lung cancer cell line A549 was obtained from American Type Culture Collection. The cells were grown in RPMI1640 supplemented with penicillin, streptomycin, and $10 \%$ fetal bovine serum (Gibco-China, Shanghai, China). CCK-8 kit was purchased from SigmaChina (Shanghai, China). Annexin V-FITC/PI apoptosis detection kit was purchased from BectonDickinson Company (Franklin Lakes, NJ, USA).

\section{Detection of cellular growth inhibition rate with CCK-8 kit}

A549 cells taken from the logarithmic growth phase in good condition were inoculated in a 96-well plate, each well containing $3 \times 10^{3}$ cells. The culture medium was discarded after culture for $24 \mathrm{~h}$ and $100 \mu \mathrm{L}$ of capecitabine at different concentrations $(0,25,50,100,250$, and $500 \mu \mathrm{M})$ diluted with RPMI 1640 medium. The growth inhibition rate was detected with CCK- 8 kit according to the manual. Briefly, CCK-8 (1:100) was added to the wells after treatment with capecitabine for 24,48 , and $72 \mathrm{~h}$, respectively, and the wells were cultured continuously for $4 \mathrm{~h}$. The absorbance at $490 \mathrm{~nm}$ wavelength was measured and the growth inhibition rate was calculated.

\section{Determination of cellular apoptosis}

A549 cells taken from the logarithmic growth phase in good condition were inoculated in 6-well plate, each well containing $2 \times 10^{5}$ cells. They were treated with $100 \mu \mathrm{M}$ capecitabine for $24 \mathrm{~h}$, with $\mathrm{y}-\left[{ }^{60} \mathrm{Co}\right] 8 \mathrm{~Gy}$ radiation for $6 \mathrm{~h}$, and then washed twice with PBS. The cells were digested with $0.25 \%$ pancreatin:PBS $=1: 1$ digestive solution. The digested cells were centrifuged at $1000 \mathrm{r} / \mathrm{min}$ for $5 \mathrm{~min}$ and the supernatant was discarded. The collected cells were washed twice with RPMI1640. The apoptosis was determined with Annexin V-FITC/PI Apoptosis Detection Kit according to the manual. AnnexinV/PI was added to the cells, which were then incubated at room temperature for $15 \mathrm{~min}$, avoiding light. The apoptosis was determined with flow cytometry. 


\section{Detection of cell cycle distribution}

After treatment with capecitabine and radiation, the cells were collected by centrifugation. The cells were washed twice with PBS and re-suspended with pre-cooling PBS; pre-chilled ethanol was added and incubated on ice for $5 \mathrm{~h}$. After washing, 1\% ethidium iodide containing RNA enzyme was added for $30 \mathrm{~min}$ to stain the cells. The cell cycle distribution was detected with flow cytometry.

\section{Statistical analysis}

The experimental data were expressed as (Mean \pm SD). All statistical analysis was done using SPSS 18.0 for Windows (IBM SPSS, Chicago, IL, USA.). The results were analyzed with one-way ANOVA and t-test to determine the significant differences. $P<0.05$ was considered statistically significant.

\section{RESULTS}

\section{Effects of capecitabine on the proliferation of A549 cells}

A549 cells were treated with $25,50,100,250$, and $500 \mu \mathrm{M}$ capecitabine. Their inhibition rates were $2.4 \pm 3.3,6.8 \pm 2.1,13.6 \pm 4.2,28.4 \pm 3.8$, and $40.5 \pm 4.0 \%$, respectively, after treatment for $24 \mathrm{~h}$; after $48 \mathrm{~h}$, the inhibition rates were $6.5 \pm 3.2 \%, 11.4 \pm 3.5,18.2 \pm 3.1,37.1 \pm 3.8$, and 57.2 $\pm 4.4 \%$ respectively; and after treatment for $72 \mathrm{~h}$, the inhibition rates were $17.6 \pm 2.4,28.8 \pm 2.1$, $39.3 \pm 3.3,58.8 \pm 4.5$, and $74.7 \pm 5.8 \%$, respectively. There were statistically significant differences in the inhibition rate between groups with different drug concentrations and different action time $(P$ $<0.05)$. The growth inhibition curve is shown in Figure 1.

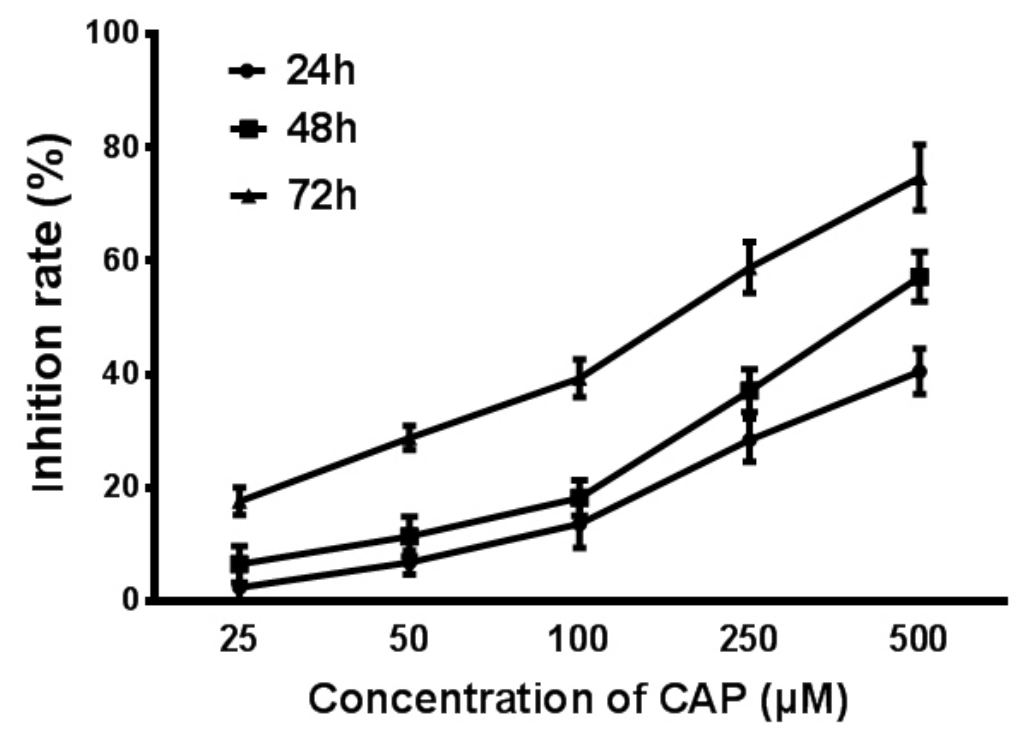

Figure 1. Inhibitory activity of different concentrations of capecitabine on the proliferation of A549 cells. 


\section{Detection of the effect of capecitabine on the apoptosis of A549 cells after radiotherapy with flow cytometry}

The results of flow cytometry showed that $A 549$ cells had a low apoptosis rate when treated with capecitabine; however, apoptosis could be induced. Compared with the control group, the apoptosis rate of the radiotherapy group increased obviously, and the apoptosis rate of the group pretreated with capecitabine prior to radiation was significantly higher than that of the radiotherapy group. Results are shown in Figure 2.
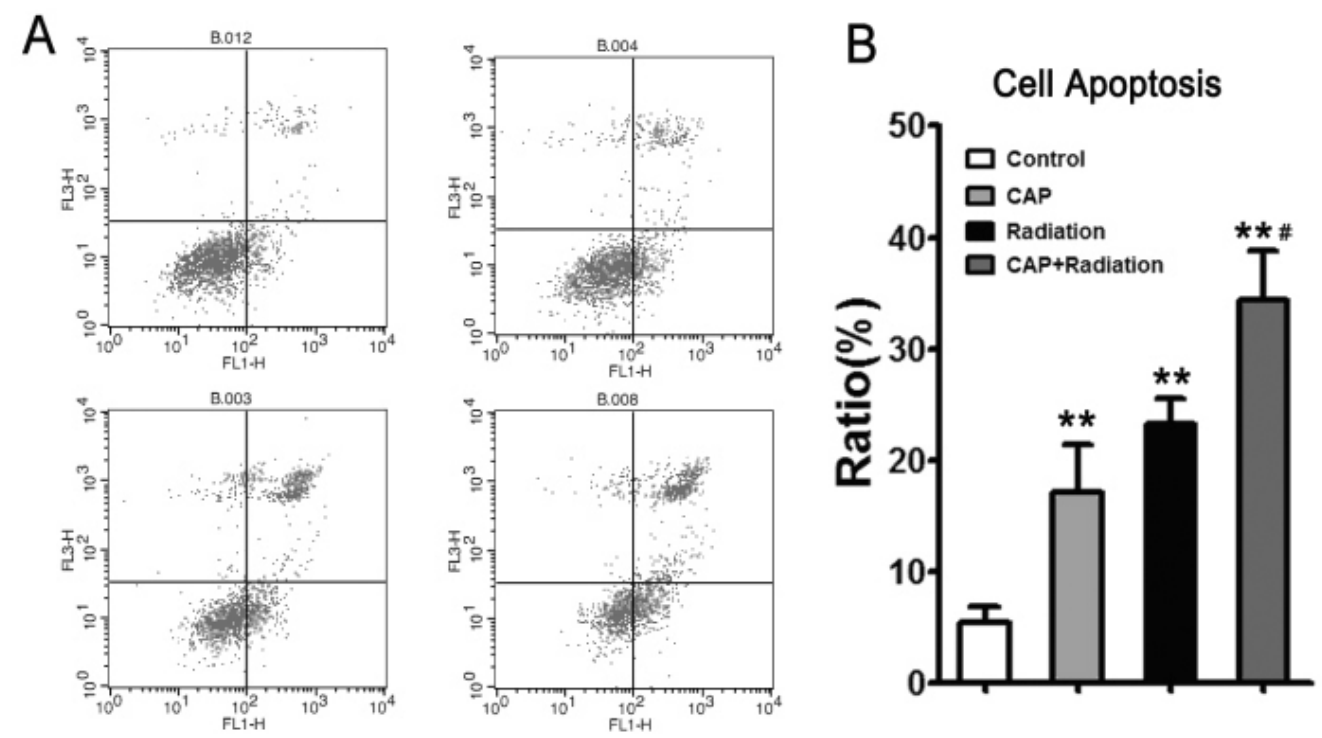

Figure 2. Effects of capecitabine on the apoptosis of A549 cells after radiotherapy. ${ }^{* *} \mathrm{P}<0.01$ vs Control, ${ }^{\#} \mathrm{P}<0.05$ vs radiation.

\section{Detection of the effect of capecitabine on the cell cycle of A549 cells after radiotherapy with flow cytometry}

The cell cycle distribution of A549 cells changed significantly after radiotherapy. When compared with the control group, the ratio of cells in the G0/G1 phase increased and the ratio of cells in the S phase decreased significantly in the capecitabine group, radiotherapy group, and capecitabine combined with radiotherapy group. Pretreatment with capecitabine significantly inhibited the cell cycle G0/G1 phase of A549 after radiotherapy. These results are shown in Table 1.

Table 1. Effects of capecitabine on cell cycle of A549 cells after radiotherapy.

\begin{tabular}{lccr}
\hline Group & G0/G1 & S & G2/M \\
\hline Control & $21.3 \pm 1.21$ & $51.4 \pm 0.38$ & $27.3 \pm 1.45$ \\
CAP & $52.1 \pm 0.63^{*}$ & $29.7 \pm 1.86^{*}$ & $18.2 \pm 1.14$ \\
Radiation & $44.7 \pm 1.09^{*}$ & $37.8 \pm 0.97^{*}$ & $17.5 \pm 0.83$ \\
CAP+ radiation & $72.5 \pm 1.24^{* \#}$ & $16.4 \pm 1.06^{* \#}$ & $11.1 \pm 1.41$ \\
\hline
\end{tabular}

${ }^{*} \mathrm{P}<0.05$ vs control, ${ }^{\#} \mathrm{P}<0.05$ vs radiation. 


\section{DISCUSSION}

Worldwide, lung cancer is one of the most common malignant tumors, with non-small-cell lung cancer (NSCLC) accounting for about 85\% (Siegel et al., 2012). At present, effective therapy is very limited and the mortality rate from NSCLC is high, which seriously affects human health. With the continuous advancements in radiotherapy, it has been reported that total-dose radiation therapy can improve the survival rate of patients with non-small-cell lung cancer (Suntharalingam et al., 2012) and high-dose hypofractionated proton beam radiation therapy is safe and effective for central and peripheral early-stage non-small-cell lung cancer (Aumont-le et al., 2011; Bush et al., 2013). However, in the actual clinical practice, it was found that lung, liver, intestine, kidney, and spinal cord cancers were tolerant to radiation (Jansen et al., 2007). Tolerance to radiation has become one of the most challenging problems in cancer therapy. Cells undergo a complicated pathophysiological process after receiving radiation, involving abnormal activation of multiple signaling pathways (Jung et al., 2010; Xu et al., 2011), DNA damage of genes, the abnormal expression of proteins with the capacity of promoting DNA repair (Kasid et al., 1987; Kitahara et al., 2002; Fukuda et al., 2004), angiogenesis (Magnon et al., 2007), autophagy (Chaachouay et al., 2011; Zhuang et al., 2011), and apoptosis (Silva et al., 2014). Although these findings help to raise awareness and understanding of the cell radiosensitivity, the mechanism of this process is not clear.

Conventional chemotherapeutic agents include etoposide, platinum agents, anthracyclines, streptozotocin, and 5-fluorouracil (5-FU) (Jensen and Delle 2011). 5-FU is the first radiotherapy sensitizer used in clinical practice; its mechanism is thought to be inhibition of DNA synthesis by inhibition of thymidylate synthase (Tano et al., 2013). Others have reported that 5-FU could significantly inhibit the proliferation of A549 cells and prolong the cell cycle (Ham et al., 2013), and induce the apoptosis of PANC-1 cells (Lee et al., 2013). Capecitabine has been widely used in the radiotherapy of gastrointestinal cancer and breast cancer as an oral 5-FU pro-drug (Zhou et al., 2013; Saif 2014; Wang et al., 2014). In this study, we found that capecitabine could obviously inhibit the growth of A549 with dose and time dependence. Pretreatment with capecitabine significantly inhibited the cell cycle G0/G1 phase of A549 after radiotherapy. Capecitabine could induce cellular apoptosis. Both capecitabine and radiotherapy could cause cell arrest in the G0/G1 phase.

Capecitabine had obvious inhibitory effects on A549 cells. Its mechanism may be related to the changed cell cycle distribution and the increased sensitivity to radiotherapy that it induces. These could provide new ideas for the treatment of non-small-cell lung cancer.

\section{Conflicts of interest}

The authors declare no conflict of interest.

\section{REFERENCES}

Aumont-le Guilcher M, Prevost B, Sunyach MP, Peiffert D, et al. (2011). High-dose-rate brachytherapy for non-small-cell lung carcinoma: a retrospective study of 226 patients. Int. J. Radiat. Oncol. Biol. Phys. 79: 1112-1116.

Bush DA, Cheek G, Zaheer S, Wallen J, et al. (2013). High-dose hypofractionated proton beam radiation therapy is safe and effective for central and peripheral early-stage non-small cell lung cancer: results of a 12-year experience at Loma Linda University Medical Center. Int. J. Radiat. Oncol. Biol. Phys. 86: 964-968.

Chaachouay H, Ohneseit P, Toulany M, Kehlbach R, et al. (2011). Autophagy contributes to resistance of tumor cells to ionizing radiation. Radiother. Oncol. 99: 287-292. 
Fukuda K, Sakakura C, Miyagawa K, Kuriu Y, et al. (2004). Differential gene expression profiles of radioresistant oesophageal cancer cell lines established by continuous fractionated irradiation. Br. J. Cancer 91: 1543-1550.

Ham MS, Lee JK and Kim KC (2013). S-adenosyl methionine specifically protects the anticancer effect of 5-FU via DNMTs expression in human A549 lung cancer cells. Mol. Clin. Oncol. 1: 373-378.

Hameed $\mathrm{H}$ and Cassidy J (2011). Use of capecitabine in management of early colon cancer. Cancer Manag. Res. 3: 295-299.

Jansen EP, Saunders MP, Boot H, Oppedijk V, et al. (2007). Prospective study on late renal toxicity following postoperative chemoradiotherapy in gastric cancer. Int. J. Radiat. Oncol. Biol. Phys. 67: 781-785.

Jensen RT and Delle Fave G (2011). Promising advances in the treatment of malignant pancreatic endocrine tumors. N. Engl. J. Med. 364: 564-565.

Jung IL, Kang HJ, Kim KC and Kim IG (2010). PTEN/pAkt/p53 signaling pathway correlates with the radioresponse of nonsmall cell lung cancer. Int. J. Mol. Med. 25: 517-523.

Kasid U, Pfeifer A, Weichselbaum RR, Dritschilo A, et al. (1987). The raf oncogene is associated with a radiation-resistant human laryngeal cancer. Science 237: 1039-1041.

Kitahara O, Katagiri T, Tsunoda T, Harima Y, et al. (2002). Classification of sensitivity or resistance of cervical cancers to ionizing radiation according to expression profiles of 62 genes selected by cDNA microarray analysis. Neoplasia 4: 295-303.

Lee JH, Lee HB, Jung GO, Oh JT, et al. (2013). Effect of quercetin on apoptosis of PANC-1 cells. J. Korean Surg. Soc. 85: 249-260.

Magnon C, Opolon P, Ricard M, Connault E, et al. (2007). Radiation and inhibition of angiogenesis by canstatin synergize to induce HIF-1alpha-mediated tumor apoptotic switch. J. Clin. Invest. 117: 1844-1855.

Miger J, Holmqvist A, Sun XF and Albertsson M (2014). Low-dose capecitabine (Xeloda) for treatment for gastrointestinal cancer. Med. Oncol. 31: 870.

Saif MW (2014). Management of a patient with metastatic colorectal cancer and liver metastases. Case Rep. Oncol. Med. 2014: 790192.

Siegel R, DeSantis C, Virgo K, Kevin S, et al. (2012). Cancer treatment and survivorship statistics. 2012. CA Cancer J. Clin. 62: 220-241.

Silva MF, Khokhar AR, Qureshi MZ and Faroogi AA (2014). lonizing Radiations Induce Apoptosis in TRAIL Resistant Cancer Cells: in vivo and in vitro analysis. Asian Pac. J. Cancer Prev. 15: 1905-1907.

Suntharalingam M, Paulus R, Edelman MJ, Krasna M, et al. (2012). Radiation therapy oncology group protocol 02-29: a phase II trial of neoadjuvant therapy with concurrent chemotherapy and full-dose radiation therapy followed by surgical resection and consolidative therapy for locally advanced non-small cell carcinoma of the lung. Int. J. Radiat. Oncol. Biol. Phys. 84: 456-463.

Tano T, Okamoto M, Kan S, Bando T, et al. (2013). Immunochemoradiotherapy for patients with oral squamous cell carcinoma: augmentation of OK-432-induced helper T cell 1 response by 5-FU and X-ray irradiation. Neoplasia 15: 805-814.

Wang F, Wang FH, Bai L and Xu RH (2014). Role of capecitabine in treating metastatic colorectal cancer in Chinese patients. Onco. Targets Ther. 7: 501-511.

Xu D, Allsop SA, Witherspoon SM, Snider JL, et al. (2011). The oncogenic kinase Pim-1 is modulated by K-Ras signaling and mediates transformed growth and radioresistance in human pancreatic ductal adenocarcinoma cells. Carcinogenesis 32 : 488-495.

Zhou Y, Peng L, Li Y and Chen L (2013). Prophylactic pyridoxine was not able to reduce the incidence of capecitabine-induced hand-foot syndrome: A meta-analysis. Biomed. Rep. 1: 873-878.

Zhuang W, Li B, Long L, Chen L, et al. (2011). Induction of autophagy promotes differentiation of glioma-initiating cells and their radiosensitivity. Int. J. Cancer 129: 2720-2731. 